\title{
Enamel remineralization after extracoronal bleaching using nano-hydroxyapatite (nHA) from synthesis results of blood clam (anadara granosa) shells
}

\author{
Noor Hikmah, ${ }^{1}$ Juni J. Nugroho, ${ }^{1 *}$ Nurhayaty Natsir, ${ }^{1}$ Christine A. Rovani, ${ }^{1}$ \\ Latief Mooduto ${ }^{2}$
}

Abstract

Objective: Nano-hydroxyapatite ( $\mathrm{nHA}$ ) is considered effective in stimulating the occurrence of enamel remineralization after application of bleaching materials. Nano-hydroxyapatite (nHA) can be synthesized from the shell of the blood clam (anadara granosa) and the substances contained can be measured using $X$-ray diffraction (XRD).

Material and Methods: The samples used in this study were 6 premolars of one upper jaw prepared by buccal and palatal crown with size of $5 \times 5 \times 2 \mathrm{~mm}$ (12 enamel disc), soaked in saline solution then divided into 2 treatment groups. Initial calcium percentage examinations were performed on each sample before bleaching material application. Next, bleaching material was applied to the sample according to the manufacturer's instructions and calcium level in each treatment group was re-examined. Application of CPP-ACP paste and nHA synthesis of blood clam (anadara granosa) shells was performed after bleaching with an hour application time per day for 7 consecutive days and re-examined afterwards. The calcium percentage examination is performed using energy dispersive $\mathbf{X}$-ray spectroscopy (EDS) tools. Data are collected and examined.

Results: Data were collected and analyzed using independent $t$ test. The results indicate that remineralization with $\mathrm{nHA}$ from synthesis results of blood clam shells increased the calcium levels of samples that had been extracoronally bleached, but statistically there was no significant difference with the value of $p=0.345$ ( $p>0.05$ ).

Conclusion: The nano-hydroxyapatite ( $\mathrm{nHA}$ ) application of blood clam shells (anadara granosa) synthesis results can increase the percentage of calcium after the application of extracoronal bleaching materials.
${ }^{1}$ Department of Conservative Dentistry, Faculty of Dentistry, Hasanuddin University, Makassar, Indonesia

${ }^{2}$ Department of Conservative Dentistry, Faculty of Dentistry, Airlangga University, Surabaya, Indonesia
"Correspondence to: Juni J. Nugroho, Department of Conservative Dentistry, Faculty of Dentistry, Hasanuddin University, Makassar, Indonesia

jektijuni@unhas.ac.id

jektijuni@yahoo.co.id

Received: 1 January 2018 Revised: 18 February 2019

Accepted: 5 March 2019

Keywords: Blood clam shells, Extracoronal bleaching, Remineralization

Cite This Article: Hikmah N, Nugroho JJ, Natsir N, Rovani CA, Mooduto L. 2019. Enamel remineralization after extracoronal bleaching using nano-hydroxyapatite (nha) from synthesis results of blood clam (anadara granosa) shells. Journal of Dentomaxillofacial Science 4(1): 28-31. D0I: 10.15562/jdmfs.v4i1.691

\section{Introduction}

Currently, the technology of dentistry materials is developing very rapidly along with public's increasing need of cosmetic dentistry. Aesthetic teeth are crucial, including tooth color. Dental discoloration, especially in anterior teeth, can cause psychological impact. $^{1}$

A wide variety of treatments are available to help fix or improve dental aesthetics. The current trend of treatment is "minimal intervention dentistry", bleaching is one the conservative method of treatment options compared to restoration methods. Bleaching procedure is relatively simple and cheap also result on aesthetic satisfaction on vital and nonvital teeth., ${ }^{2,3}$

Bleaching is a chemically tooth whitening treatment on discolored teeth using oxidant or strong reductor. Bleaching ingredients are carbamide peroxide, sodium perborate and hydrogen peroxide. Hydrogen peroxide is the most commonly applied material because it takes a shorter time in its application. ${ }^{1,3}$

Application of bleaching materials inflict side effects of demineralization and dentinal tubules widening resulting in an increase of tooth sensitivity and weakening of tooth structure. ${ }^{1-3}$
Demineralization process occurs due to release of calcium $(\mathrm{Ca} 2+)$ bonds from Ca10(PO4)6(OH)2 hydroxyapatite phosphate compound and enamel mineral composition especially the amount of calcium and phosphate..$^{1-6}$

Demineralization causes a decrease in microhardness and resistance to fracture as well as susceptibility to erosion and abrasion. Various ways can be performed to reduce the side effects of bleaching material applications by stimulating the emineralization or rearrangement of enamel hydroxyapatite structures, one of them with fluoride applications as well as materials that contain calcium and phosphate, in this case hydroxyapatite (HA), especially in the form of nanoparticleshydroxyapatite (nHA) that is considered effective in enamel remineralization. ${ }^{3,4}$

Nano-hydroxyapatite (nHA) is the largest component of the chemical structure of enamel. Hydroxyapatite can be synthesized from natural ingredients such as egg shells, cow bones, corals and clam shells. Previous studies have reported that the percentage of calcium and HA forming phosphate found in shell fish is higher than that of other natural ingredients, especially clam family archidae, 
Table 1 Content of blood clam shells synthesis results

\begin{tabular}{lc}
\hline Compound & Percentage \\
\hline Hydroxyapatite $\beta$ - tricalcium & $59 \%$ \\
phosphate & $38 \%$ \\
$\mathrm{CaO}$ & $1.5 \%$ \\
$\mathrm{Ca}(\mathrm{OH})_{2}$ & $0.7 \%$ \\
\hline
\end{tabular}

Table 2 Percentage differences of calcium levels at initial, after bleaching, and after remineralization in each intervention group

\begin{tabular}{|c|c|c|c|c|}
\hline \multirow{3}{*}{ Intervention } & \multicolumn{3}{|c|}{ Percentage of Calsium Levels } & \multirow{3}{*}{ p-value } \\
\hline & Initial & After Bleac & After Remineralization & \\
\hline & Mean $\pm S D$ & Mean $\pm S D$ & Mean \pm SD & \\
\hline \multirow{2}{*}{$\begin{array}{l}\text { CPP - APP } \\
\text { Shells of } \\
\text { blood clams }\end{array}$} & $49.70 \pm 5.83 \mathrm{a}$ & $49.54 \pm 5.89 \mathrm{a}$ & $51.69 \pm 3.99 \mathrm{a}$ & $0.513^{*}$ \\
\hline & $46.00 \pm 5.28 \mathrm{a}$ & $52.04 \pm 3.41 \mathrm{~b}$ & $54.68 \pm 2.36 \mathrm{~b}$ & $0.024 * *$ \\
\hline
\end{tabular}

Normality test, ${ }^{\mathrm{a}}$ Shapiro-Wilk test; $\mathrm{p}<0.05$ : data distribution not normal

${ }^{\mathrm{b}}$ Shapiro-Wilk test; $\mathrm{p}>0.05$ : data distribution normal

*Friedman test; $\mathrm{p}>0.05$; not significant

** Repeated Anova; $\mathrm{p}<0.05$; significant

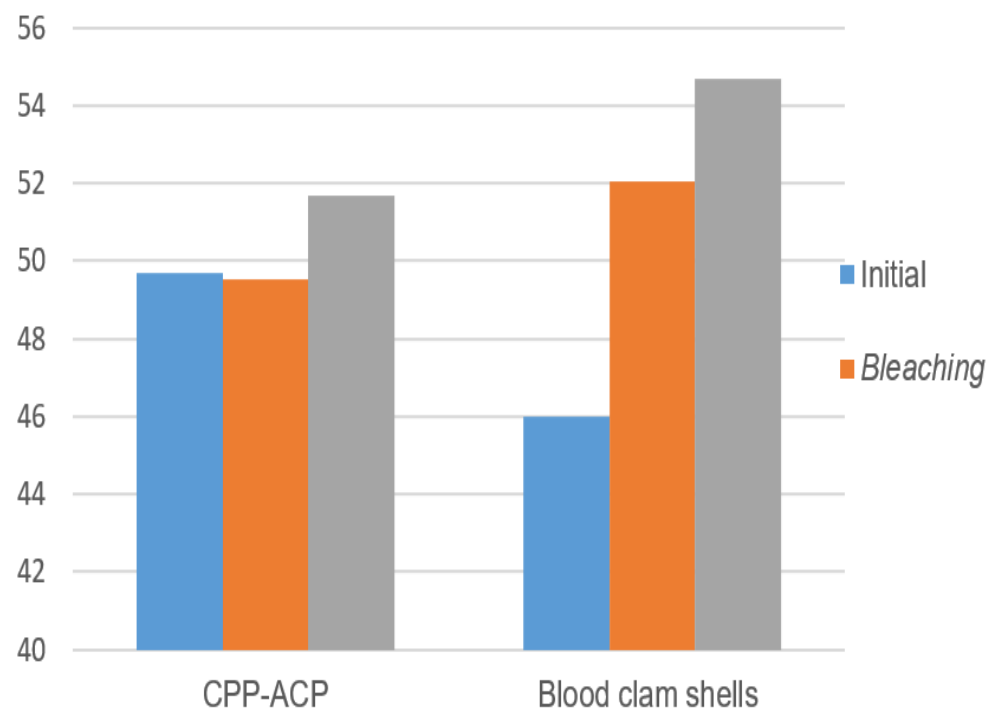

Figure 2 Histogram comparison of initial calcium percentage, after application of bleaching materials and after application of remineralization materials

one of which is a blood clam (anadara granosa). This type of shell is relatively thicker than other types of shells, thus the percentage of calcium and phosphate is higher. ${ }^{7-9}$

Samples knowledge about oral cancer among 10 cancers which occurs the most was still low. As more than half from the samples doesn't know about it. About 109 samples (70.3\%) did not know and only 46 samples $(29.7 \%)$ knew it.
Based on the above description the author would like to determine the effectiveness of hydroxyapatite material application in form of nanoparticle produced from synthetic shells of blood clams (Anadara granosa) on enamel remineralization after extracoronal bleaching.

\section{Material and Methods}

The type of this study was laboratory experiment. The experimental design is purely based on the pre-post test control group design. The samples used were 6 premolars of one upper jaw prepared by buccal and palatal crown with size of $5 \times 5 \times 2 \mathrm{~mm}$ (12 enamel disc) and soaked in saline solution then divided into 2 treatment groups. Initial calcium percentage examinations were performed on each sample before bleaching material application. Furthermore, the bleaching material was applied to the samples according to the manufacturer's instruction that is $2 \times 20$ minutes and then calcium levels in each treatment group are re-examined. Application of CPP-ACP paste and nHA synthesis of blood clam shells (anadara granosa) was performed after bleaching with 1-hour application time per day for 7 consecutive days and re-examined afterwards. The calcium percentage examination is performed using the energy dispersive $\mathrm{x}$-ray spectroscopy (EDS) tool.

\section{Results}

Table 1 reveals the mineral content of blood clam shell synthesis that was examined using X-Ray Diffraction to observe and measure the compound formed. Measurement results can be observed in the following table.

Table 2 the results showed that the percentage of initial calcium levels in CPP-ACP paste group reached $49.70 \%$. After bleaching, the percentage of calcium levels decreased to $49.54 \%$. However, calcium levels re-increased after remineralization to $51.69 \%$. The statistical results showed that $\mathrm{p}=0.513$ ( $p>0.05$ ), which means that there was no significant difference in calcium levels at initial, after bleaching, and after remineralization in the CPP-ACP paste group as a positive control. The results also showed the percentage of calcium level in the group of blood clam shell paste, showing an average calcium content of $46 \%$. After bleaching, calcium levels increased to $52.04 \%$ and after remineralization, calcium levels re-increased to $54.68 \%$. The statistical results showed that $\mathrm{p}=0.024(\mathrm{p}<0.05)$, indicated that there was significant difference of calcium levels between the initial group, after bleaching, and after remineralization in the group of blood clam shells paste figure 1. 


\section{Discussion}

In this study energy dispersive $\mathrm{x}$-ray spectroscopy (EDS) tool was applied to measure the percentage of substance contained in a sample. The advantage of using this tool is that the sample measured in percentage will not change its shape. Therefore, this tool can be used for evaluating the percentage of an substance before and after giving treatment.

The results showed that the percentage of initial calcium content and content after extracoronal bleaching in CPP-ACP group decreased significantly. According to Marson et al. ${ }^{10}$ the penetration of hydrogen peroxide into enamel are various at every concentration and brand. The faster the hydrogen peroxide penetrate into the enamel, the deeper the penetration into the enamel, which will increase the risk of the release of inorganic substances of enamel. In this study the bleaching material used was applied according to the factory that is applying on the enamel surface of the sample email for $2 \times 20$ minutes with $\pm 1-2 \mathrm{~mm}$ in material thickness. applying materials of bleaching based on the factory instruction is belived that it has not reached the saturation point (enamel break down), thus calcium percentage decrease which is occured in this treatment group is not significant.

The value of the initial nutrition and the nutrition after extracoronal bleaching in the group which will be remineralized using nHA synthesized from shells of blood calm (anadara granosa) showed that there is insignificant increase of calcium percentage. This is probably caused by residual minerals of calcium redeposited back to the sample due to a sample measurement that is not immediately done after the application of nHA. In addition, the soaking container which is only rinsed with salt content in every treatment influence existence of residue on soaking container which may increase the degree of hydroxyapatite saturation in liquid. This is agree with the theory which shows that the process of redeposited inorganic minerals into the teeth is strongly caused by various factors such as saturation of the solution towards teeth, rate of sedimentation solution, $\mathrm{pH}$ of the solution and time. ${ }^{11,12}$

The percentage of calcium before and after bleaching in the sample group which would be remineralized using CPP-ACP and nHA synthesized from the shellfish shell (anadara granosa) showed insignificant change. This study agree with research conducted by Hegedus et al. ${ }^{13}$ using atomic force microscopy which would influence the change of enamel structure as well as some other researchers who report that the use of that material does not cause email change.
Statistically, there is insignificant improvement between the use of these two remineralization materials. It occurs because of the application of both materials that are only done 1 hour per day for 7 days respectively. Descriptively, the group of samples given therapeutic remedial therapy, both CPP-ACP and nHA synthesis of shells of blood calms (Anadara granosa) showed an increase in the percentage of calcium. This increase occurs because both of these materials contain elements and compounds that can stimulate remineralization of inorganic minerals such as calcium, phosphate or fluor. ${ }^{14}$

The highest increase of nutrition percentage is occured in treatment group nHA synthesized from shellfish shell (anadara granosa) compared to CPP-ACP paste group. This is because the calcium content in nHA synthesized from shells of blood calms (anadara granosa) is higher (53\%) when compared to CPP-ACP containing only $18 \%$ calcium (GC Tooth-Mousse). In addition, nHA synthesized from shells of blood calms (anadara granosa) contains calcium hydroxide. Calcium hydroxide has a high $\mathrm{pH}$ that can affect remineralization. Remineralization can occur not only because of the inorganic minerals but also the high $\mathrm{pH}$ condition. However, the use of these two materials can be carried out by itself descriptively. This result that the CPP-ACP paste applications and hydroxyapatite pastes can cause enamel remineralization after applying $40 \%$ hydrogen peroxide in in-officebleaching technique. ${ }^{15}$

\section{Conclusion}

In the limitation of this study, concluded that application of nHA synthetized from shells of blood calms (anadara granosa) and CPP-ACP able to increase mineral percentage of enamel after application of extracoronal bleaching material.

\section{Acknowledgment}

We are very grateful for all parties involved in this research.

\section{Conflict of Interest}

The authors report no conflict of interest.

\section{References}

1. Rotstein I, Walton RE. Bleaching discolored teeth: Internal and external. In: Walton RE, Torabinejad M, eds. Principle and practice of endodontics 4th ed, Philadelphia: W.B. Saunders Company; 2009. p. 391. 
2. Rastelli ANS, Nicolodelli G, Romano RA, et al. After bleaching enamel remineralization using a bioactive glass-

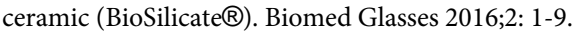

3. Junqueira RB, Carvalho RF, Carmo AMR, et al. In vitro analysis of human enamel microhardness as subjected to prolonged use of external bleaching agents. UNOPAR Cient Cienc Biol Saude 2013;15: 141-143.

4. Vasconcelos AAMD, Cunha AGG, Borges BCD, et al. Enamel properties after tooth bleaching with hydrogen/ carbamide peroxides in association with a CPP-ACP paste. Acta Odontol Scandinavia 2012;70: 337.

5. Mihu CM, Dudea D, Melincovici C, et al. Tooth enamel, the result of the relationship between matrix proteins and hydroxyapatite crystals. App Med Informatics 2008;23: 68-72.

6. Bharatham $\mathrm{H}, \mathrm{Zakaria} \mathrm{ZAB}$, Perimal EK, et al. Mineral and physiochemical evaluation of cockle shell (anadara granosa) and other selected mulloscan shell as potential biomaterials. Sains Malaysiana 2014;43: 1023-1029.

7. Lee SW, Balazsi C, Balazsi K, et al. Comparative study of hydroxyapatite prepared from seashells and eggshells as a bone graft material. Tissue Eng Regenerative Med 2014;11: 113-120.

8. Alqahtani MQ. Tooth-bleaching procedures and their controversial effects: a literature review. Saudi Dent J 2014;26: 33-46.

9. Hegde MN, Shetty KR, Shetty S. Overview of in-office bleaching of vital teeth. IRJP 2012;3: 12-16.
10. Marson FC, Goncalves RS, Silva CO, et al. Penetration of hydrogen peroxide and degradation rate of different bleaching products. Operative Dentist 2014;39: 1-8.

11. Fearon J. Tooth whitening: concepts and controversies. Int Dent SA 2007;11: 24-38.

12. Khiri MZA, Matori KA, Zainuddin N. The usability of ark clam shell (anadara granosa) as calcium precursor to produce hydroxyapatite nanoparticle via wet chemical precipitate method in various sintering temperature. Springer Plus 2016;5: 1-15.

13. Hegedus C, Bistey T, Flora-Nagy E, et al. An atomic force microscopy study on the effect of bleaching agents on enamel surface. J Dent 1999;27: 509-515.

14. Reema SD, Lahiri PK, Roy SS. Review of casein phospohopeptides-amorphous calcium phosphate. Chinese J Dent Res 2014;17: 7-13.

15. Valera MC, Camargo CHR, Carvalho CAT, et al. Effectiveness of carbamide peroxide and sodium perborate in nonvital discolored teeth. J Appl Oral Sci 2009;17: 254-261.

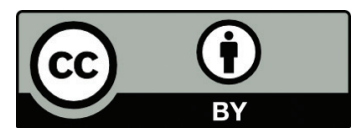

This work is licensed under a Creative Commons Attribution 